\title{
COMPARISON OF ALLELOPATHIC POTENTIAL OF SRI LANKAN TRADITIONAL RICE VARIETIES (Oryza sativa L.) USING RADISH (Raphanus sativus L.) AS AN INDICA- TOR PLANT
}

\author{
AS Ranagalage ${ }^{1}$ and DL Wathugala ${ }^{2 *}$ \\ ${ }^{1}$ Faculty of Graduate studies, University of Ruhuna, Sri Lanka \\ ${ }^{2}$ Department of Crop Science, Faculty of Agriculture, University of Ruhuna, Mapalana, Kambu- \\ rupitiya, Sri Lanka
}

Accepted: $28^{\text {th }}$ May 2015

\begin{abstract}
Allelopathy is the direct influence of an organic substances released from one plant on the growth and development of other plants. To avoid the hazardous and indiscriminate use of chemicals for weed control in paddy fields much concerns were deposited on proper assessment and manipulation of allelopathic properties of rice plants. There is a huge variation in allelopathic potential among rice varieties. Therefore, in this experiment relay seeding technique without soil (experiment 1) and with soil as a medium (experiment 2) were conducted under laboratory condition to observe and screen the allelopathic potential of selected Sri Lankan traditional rice varieties on seed germination, shoot and root length and dry matter production of radish (Raphanus sativus) as a phototoxic sensitive test crop. Significant differences $(p \leq 0.05)$ were observed among different rice varieties in terms of seed germination and growth inhibition of radish. The dry weight accumulation of rice cultivars ranged from 12.5$\mathbf{7 6 . 3 \%}$ in experiment 1 and $\mathbf{1 5 . 9 - 7 9 . 9 \%}$ in experiment 2 . All tested varieties of rice performed inhibitions to studied characters of radish. In both experiments, the highest dry weight reductions were noticed with rice varieties Pachchaperumal and Herathbanda. Both the evaluation methods were positively correlated in determining percent reduction in all the measured parameters of radish. According to the results it can be concluded that the allelopathic potential of rice varieties varies in a very broad range and out of varieties tested Pachaperumal and Herathbanda showed highest allelopathic potential against radish growth.
\end{abstract}

Key words: Allelopathy, allelochemicals, inhibition, Oryza sativa, Radish, Raphanus sativus

\section{INTRODUCTION}

Rice (Oryza sativa L.) is the principal food crop in Asia and the staple food of the majority of the population in many regions of the world. Population pressure in rice consuming countries demands that more sustainable rice production to increase quality and yield. Weeds are the crucial problem out of other circumstances which are adversely affected to the crop productivity of rice ecosystems. Due to heavy infestation of weed in paddy cultivation, rice yield and quality become deteriorate. Indiscriminate use of herbicides for weed control has caused for serious effect to the natural environment and living creatures including humans. Heavy use of herbicides is the root cause of number of inevitable primary and secondary hazards such as develop-

*Corresponding author: lakmini077@yahoo.com ment of herbicide resistant weeds (Valverde et al., 2000), shifts in weed population (Narwal and Tauro,1994) increasing environmental pollution and human exposure to toxic materials (Chung et al., 1997; Stephenson, 2000).

By concerning drawback of chemical weed control, in recent years, much concern has been raised about the positive aspects of environmental friendly and sustainable strategy of ecological weed management. Allelopathy is defined as the direct or indirect harmful or beneficial effects of one plant on another through the production of chemical compounds that escape into the environment (Rice, 1984). Chemicals released from plants and imposing allelopathic influences are termed allelochemicals. Allelochemicals can be present in several parts of plants including roots, rhizomes, leaves, stems, pollen, seeds and flowers. Allelochemicals are released into 
the environment by root exudation, leaching from aboveground parts and volatilization and/or by decomposition of plant material (Rice, 1984; Reigosa et al., 1999). This phenomenon could be an alternative weed control method.

Since Dilday et al.(1994) reveled that some rice accessions possess allelopathic activity in weed suppression, rice allelopathy has been received a great deal of attention and positive aspect as biological weed control method. A number of studies have been conducted to evaluate the allelopahic potential from rice germplasm and number of rice accessions having allopathic potential have been determined in different places (Ahn and Chung, 2000; Chou, 1995; Chou, 1999; Chung et al., 1997; Dilday et al., 1994; Fujii, 1992; Garrity et al.,1992; Hassan et al., 1994; Lin et al., 1992; Olofsdotter et al., 1995; Kim et al,1999; Olofsdotter et al.,1999; Chung et al., 1997, 2000, 2001a, 2001b; Ahn and Chung, 2000). Those experiments showed significant differences in allelopathic potential among rice varieties. Several allelochemicals were also extracted from different parts of rice plants and these chemicals are assumed to act in an additive or synergistic way rather than in an isolated way (Courtois and Olofsdotter, 1998). Some of the genes responsible for rice allelopathy have also been identified (Xu et al., 2011; Xuan et al., 2005). However, so far a rice variety with higher allelopathic potential has not been developed. Although, it has been proved that the allelopathic potential of rice on weeds could be applied to reduce use of harmful synthetic herbicides, a proper study on allelopathic potential of commonly cultivating Sri Lankan traditional rice varieties has not been conducted.

The major ways which plants emit allelochemicals to the environment are (1) plant residue itself or emission separated by microorganisms; (2) emission of water-soluble substances from plant root into the surrounding environments; (3) secretion of water soluble substances from plants above ground and come to the soil by rain, mist and/or dew; and (4) emission of gaseous substances from plant above ground to the atmosphere (Jonghan et al., 2005). The substances found in plants are alkaloids, flavonoids, phenolics, terpenoids, lactones, tannins, cyanogenic glucosides, quinones, polyacetylenes, coumarins, sulfides and plant organic acids (Dilday et al., 1991). According to the Rimando et al. (2001) and Olofsdotter et al. (2001), most allelochemicals reported in rice were phenolic compounds and were found in leaf, straw, stem and rice soil rather than husk.

Allelophthic potential and resource competition is difficult to separate under field conditions. As a remedy for the above problem various laboratory screening techniques have been developed to measure allelopathy, separating from the interference of resource competition. Several authors reviewed the importance and necessity of laboratory bioassays for initial allelopathic investigation in rice cultivars. Many researchers have been showed that bioassays are the most convenient, effective and simplest way to estimate the allelopathic potential of rice as comparatively large number of rice cultivars can be examined in a limited time and space all year round (Khanh et al., 2007). Among several bioassays, sandwich method (Fujii et al., 2003), agar medium selection (Fujii, 1992; Wu et al., 1999), plant box method (Khanh et al., 2007) and relay seedling method (Navarez and Olofsdotter, 1996) have been reported and tested for bioassays. Lettuce (Lactuca sativa L.), radish (Raphanus sativus) and cress (Lepidium sativum L.) were commonly used as indicator plants in those laboratory bioassays to screening rice allelopathy.

Traditional rice varieties have been conserved, developed and used by Sri Lankan farmers over a period of more than 3000 years. However, with the introduction of high yielding varieties along with modern agronomic practices most traditional rice varieties were re- 
placed by handful of high yielding rice varieties causing severe losses in rice genetic diversity. Although scientific studies have not been proved different historical records reveal that traditional rice varieties were revered for their nutritional and medicinal properties. Therefore, now there is a trend in cultivating traditional varieties by small scale farmers. Plant Genetic Resource Center (PGRC) Gannoruwa, has conserved more than 2000 traditional rice accessions collected from farmers fields in Sri Lanka. Apart from them some farmer federations such as 'Farmer Federation for Conservation of Traditional Seeds and Agri-Resources (FFCTS\&AR)' are also cultivating and conserving traditional rice varieties.

The present study was undertaken to examine the influence of commonly cultivating Sri Lankan traditional rice varieties on seed germination and growth of radish and thereby evaluate the allelopathic potential of those rice varieties.

\section{MATERIALS AND METHODS}

\section{Plant materials}

Thirty commonly cultivating Sri Lankan traditional rice varieties (Table 1) were used in this study. The selected rice varieties were collected from "Farmer Federation for Conservation of Traditional Seeds and AgriResources (FFCTS\&AR)" and the radish (Raphanus sativus var. Local) seeds were collected from the local market. The initial germination of the collected seeds was more than $80 \%$.

\section{Relay seeding method without soil}

The relay seedling method described by Kabiret al. (2010) was followed in this study. Presoaked 20 rice seeds were placed on the Petri dishes (9 $\mathrm{cm}$ in diameter) with Whatman No. 1 filter paper. Similar amount of distilled water was poured in each Petri dish to moist filter papers. Then the Petri dishes were kept at the laboratory conditions. The average room temperature ranged from $27^{\circ}$ to $29^{\circ} \mathrm{C}$. Fifteen clean and 12 hours water soaked seeds of radish were placed in each Petri dish after 7 days of placement of rice seeds. In control treatment, 15 seeds of radish were placed in petri dish lined with soaked filter paper. The experiment was continued for another 7 days under the laboratory conditions. The treatments were replicated three times in CRD. Distilled water was added to each Petri dish every 2 days to maintain sufficient moisture for germination. The theme of this technique was that the rice seedlings released allelochemicals in the germination media and the growth of the neighboring test plant (radish) seedlings were affected due to allelochemicals.

\section{Relay seeding method with soil}

Experimental procedures were similar as described under relay seeding method without soil. However, instead to filter paper a soil mixture (top soil: sand: compost $=1: 1: 1$ ) were used to ensure more stabilization of plants in the Petri dish.

\section{Data collection}

After 7 days of seeding, number of germinated seeds, the root length and the shoot length of five randomly selected radish seedlings were measured. The sample seedlings were placed in paper bags and then kept in an electric oven at $65^{\circ} \mathrm{C}$ for $48 \mathrm{~h}$. The weights of oven dried specimens were recorded. The percent reduction in germination, root length, shoot length and dry matter accumulation was determined by using the following formula (Chung et al., 2001b)

Inhibition percentage $(\%)=[($ control-
treatment $) /$ control $] \times 100$

The collected data on different parameters of the indicator plant were statistically analyzed by using the SAS and the mean the mean separation were done using DMRT. Correlation between two methods in determining allelopathic potential of the rice varieties was also made. 
Table 1: Percent reduction in germination (GI\%), root length (RLI\%), shoot length (SLI\%) and dry matter production (DWI\%) of radish due to allelopathic effect of different rice varieties under relay seedling without soil and soil as a medium experiments.

\begin{tabular}{|c|c|c|c|c|c|c|c|c|}
\hline \multirow[b]{2}{*}{ Rice variety } & \multicolumn{4}{|c|}{$\begin{array}{c}\text { Experiment 1- Relay seeding } \\
\text { without soil }\end{array}$} & \multicolumn{4}{|c|}{$\begin{array}{c}\text { Experiment 2- Relay seeding } \\
\text { soil as a medium }\end{array}$} \\
\hline & GI\% & SLI \% & RLI \% & DWI $\%$ & $\mathrm{GI} \%$ & $\mathrm{SLI} \%$ & RLI\% & DWI\% \\
\hline Pachchaperumal & 22.2 & 63.8 & 54.8 & 76.3 & 13.3 & 69.7 & 64.3 & 79.9 \\
\hline Herathbanda & 24.4 & 58.9 & 65.5 & 71.2 & 20.0 & 58.2 & 61.3 & 77.3 \\
\hline Rathheenati & 6.7 & 16.1 & 19.8 & 28.8 & 11.1 & 15.1 & 41.5 & 46.2 \\
\hline Kaluheenati & 6.7 & 41.8 & 29.5 & 66.1 & 20.0 & 24.9 & 41.2 & 77.3 \\
\hline Sula & 8.9 & 36.2 & 24.1 & 31.4 & 2.2 & 50.8 & 53.5 & 33.0 \\
\hline Sudumurunga & 15.6 & 25.0 & 18.4 & 27.2 & 4.4 & 14.1 & 49.8 & 31.9 \\
\hline Dahanala & 22.2 & 36.2 & 18.8 & 57.5 & 11.1 & 19.5 & 45.9 & 60.0 \\
\hline Hodarawalu & 11.1 & 30.9 & 27.7 & 22.6 & 15.6 & 10.1 & 17.1 & 30.9 \\
\hline Pokkali & 4.4 & 4.4 & 12.2 & 12.7 & 6.7 & 4.5 & 8.4 & 22.6 \\
\hline Handiran & 17.8 & 19.7 & 18.5 & 14.4 & 13.3 & 18.7 & 21.6 & 38.7 \\
\hline Rathal & 6.7 & 38.6 & 21.4 & 19.4 & 8.9 & 17.5 & 18.4 & 20.7 \\
\hline Galsiyambala & 11.1 & 34.3 & 30.9 & 37.9 & 6.7 & 34.5 & 15.2 & 39.5 \\
\hline Gurusinghe wee & 6.7 & 16.2 & 15.9 & 32.1 & 4.4 & 15.0 & 24.9 & 26.7 \\
\hline Masuran & 13.3 & 54.0 & 39.0 & 72.3 & 11.1 & 55.1 & 50.7 & 68.7 \\
\hline Duru wee & 0.0 & 24.2 & 16.4 & 37.0 & 13.3 & 21.5 & 33.2 & 30.5 \\
\hline Rathkaya & 2.2 & 18.4 & 12.9 & 44.3 & 6.7 & 35.9 & 32.3 & 22.8 \\
\hline Behethheenati & 11.1 & 26.6 & 25.4 & 12.5 & 15.6 & 27.3 & 35.5 & 31.9 \\
\hline Suwal & 6.7 & 30.7 & 30.1 & 16.7 & 15.6 & 23.0 & 12.2 & 22.2 \\
\hline Batapolael & 6.7 & 35.5 & 47.6 & 48.4 & 13.3 & 44.6 & 63.6 & 45.2 \\
\hline Unakola Samba & 4.4 & 27.0 & 30.5 & 28.5 & 11.1 & 14.2 & 20.4 & 28.8 \\
\hline Murungakayan & 6.7 & 27.9 & 31.9 & 32.3 & 13.3 & 32.6 & 40.6 & 32.4 \\
\hline Madthawalu & 6.7 & 26.7 & -0.5 & 27.5 & 6.7 & 15.8 & 1.0 & 16.9 \\
\hline Gonabaru & 4.4 & 38.0 & 34.1 & 64.3 & 13.3 & 31.9 & 56.6 & 64.8 \\
\hline Hichchinanghi & 2.2 & 23.6 & 22.0 & 33.0 & 8.9 & 21.7 & 14.1 & 20.1 \\
\hline Munchalalagi & 2.2 & 31.6 & 3.0 & 32.1 & 13.3 & 11.7 & 15.3 & 22.9 \\
\hline Mudali wee & 11.1 & 29.2 & 38.7 & 54.0 & 11.1 & 41.4 & 57.6 & 53.8 \\
\hline Godaheenati & 8.9 & 16.2 & 26.9 & 34.8 & 24.4 & 24.1 & 32.9 & 24.5 \\
\hline Kurulutuda & 6.7 & 34.6 & 11.4 & 26.0 & 13.3 & 16.6 & 12.8 & 33.3 \\
\hline Suduru samba & 4.4 & 23.1 & 19.3 & 39.3 & 6.7 & 12.6 & 18.9 & 33.3 \\
\hline Wathidahathala & 6.7 & 4.4 & 1.6 & 12.8 & 6.7 & 8.7 & 8.4 & 15.9 \\
\hline $\mathrm{CV}$ & 4.8 & 4.5 & 7.9 & 3.1 & 6.4 & 7.8 & 7.1 & 2.1 \\
\hline LSD & 2.1 & 0.4 & 0.7 & 0.3 & 1.4 & 0.6 & 0.6 & 0.2 \\
\hline
\end{tabular}

RESULTS AND DISCUSSION
Among the 30 traditional rice varieties, the highest reduction in seed germination of radish under experiment conducted without a 
growing medium (experiment 1) was found with Herathbanda (24.4\%) and closely followed by Pachchaperumal and Dahanala $(22.2 \%)$ (Table 1). There was no significant difference in between these three rice varieties in terms of inhibition of radish seed germination. Contrasting results were observed in relay seeding experiment conducted using soil as a growing medium (experiment 2) (Table 1) where highest and lowest germination inhibition percentages were showed by Suduru samba $(24.4 \%)$ and Duru wee $(0.0 \%)$ respectively. All other tested varieties showed germination inhibition less than 20\% (Table 1) in both experiments.
The highest shoot length reduction was observed with rice variety Pachchaperumal in both experiments (63.8 and $69.7 \%$ respectively) (Table 1). The highest root length reduction in radish occurred with variety Herathbanda $(65.5 \%)$ in experiment 1 and variety Pachchaperumal (64.3\%) in experiment 2 (Table 1). Whereas, rice variety Madathawalu showed slight increment of root length in experiments 1 , and very low inhibition in experiment 2 (Table 1). The highest dry weight reduction in radish was also noticed with rice variety Pachchaperumal (76.3 and $79.9 \%$ respectively) in both experiments.

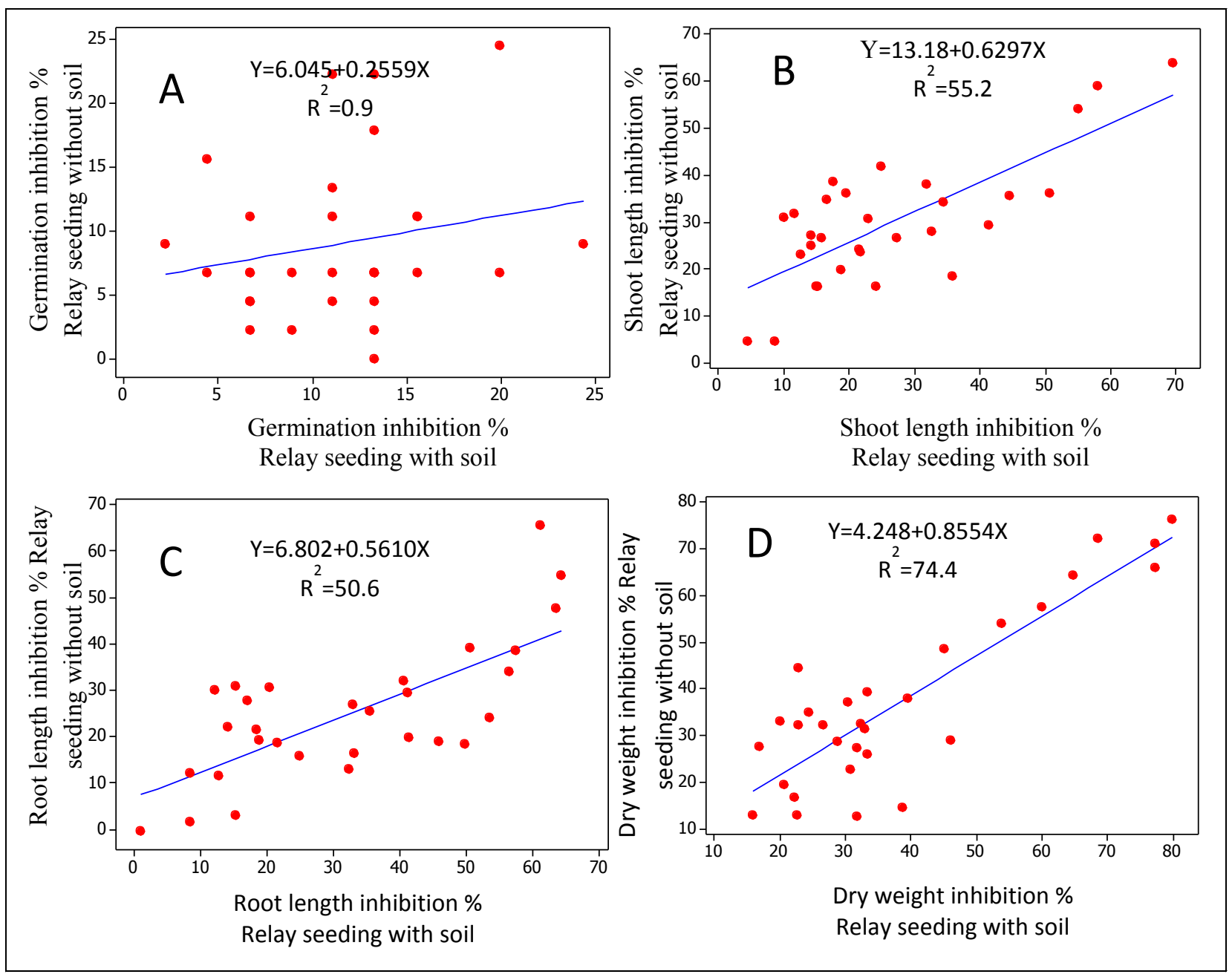

Figure 1: Correlation between two methods in measuring inhibition percentages of (A) seed germination (B) shoot length, (C) root length and (D) dry matter production of radish growth 
Except seed germination inhibition highly significant positive relationship $\left(\mathrm{R}^{2}=>50\right)$ was noticed between the two experiments in measuring shoot length, root length and dry matter accumulation of radish (Fig. 1).

The results of this study reveal that Sri Lankan traditional rice varieties have significant effects on growth and development of indicator plant radish. Several plants such as radish, lettuce, cress, cucumber are phytotoxic sensitive plants widely used in allelopathic research (Khanh et al., 2007). Therefore, it is obvious that the wide variations in measured variables of radish were due to allelochemicals released from rice plants. Karim et al. (2012) and Karim and Smail (2005) have observed growth inhibition of lettuce seeds due to allelopathic effects of rice varieties. Further, similar kind of reduction in spinach due to allelopathic effects of rice varieties was noted by Kabir et al. (2010). Allelochemicals released from plants affect biological and biochemical processes of neighbouring plants and thereby it can be observed inhibition or stimulations of the growth and development of neighbouring plant. As an example allelopathic compounds influence physiological processes such as cellular expansion, cell wall construction, phytohormonal balance, activity of specific enzymes, mineral uptake, photosynthesis, respiration, stomatal movements, protein synthesis etc. (Wink and Twardowski, 1992; Rice, 1984; Alam et al., 2001). Except the effects of many physiological processes of neighbouring plants allelochemicals modify soil properties such as soil pH (Kruse et al., 2000) and thereby indirect effects cause on plant growth and development.

In the present experiment it could be observed reduction in seed germination in both experiments (Table 1). Previous research also reports delay in seed germination due to allelochemicals (Kruse et al., 2000). Findings of these researches revealed that several allelochemicals secrete from allelopathic spe- cies are structurally similar to plant hormones (Olofsdotter, 1998). These allelopathic compounds can effect hormone induction during germination process or activity of specific enzymes such as amylases, proteinases etc. which are essential for seed germination (Rice, 1984). In the present study except few varieties most of the varieties showed less than $15 \%$ germination inhibition (Table 1) indicating that the allelopathic compounds release from tested rice varieties may not have much effect on inhibition of seed germination of radish.

The shoot and root length reduction of radish observed (Table 1) in the present study may also due to the action of allelochemicals release from rice plants. Probably these allelopathic compounds may affect the nutrient uptake of radish plants and which ultimately interfered with the development of shoot length. It is obvious that most of the allelochemicals release from roots and root system of neighboring plants affect much, and finally those effects can be seen in all parts of the plant. In the present study except Madathawalu in experiment 1 all other rice varieties showed reduced root lengths (Table 1). With some rice varieties stunted roots and browning of root tips and highly branched roots were observed. Similar kind of shoot and root length reductions and root discolorations were observed by many researches such as Karim and Ismail (2005) for E. crusgalli, Lie et al. (2004) for E. crusgalli, Karim et al. (2012) for lettuce and Kabir et al. (2010) for spinach. Kim et al. (1999) and Chung et al. (1997) also observed similar detrimental effects of rice exudates on the root length of E. crusgalli. Further, Karim and Ismail (2007) observed that rice varieties namely Manik and Makmuer caused more than $80 \%$ and $75 \%$ reduction of root length of $E$. crusgalli, respectively due to their allelopathic effect. Since allelopathic effect of rice varieties reduce shoot and rood length of radish, the dry matter accumulation of radish was also reduced (Table 1). Seedling weight is an important expression of 
size and vigor of the seedling which is an important feature for success in competition for sites, space, and nutrients (Chung and Miller, 1995).

When considering dry matter accumulation 3 rice varieties showed more than $70 \%$ inhibition in both experiments ie. Pachchaperumal, Herathbanda and Masuran in experiments 1 (table 1) and Pachchaperumal, Herathbanda and Kaluheenati in experiment 2. Therefore these varieties can be considered as rice varieties with higher allelopathic potential. These rice varieties can also be used as source of genes in rice breeding to develop high yielding and weed-suppressive rice varieties. However, future work is needed to specify and verify the allelochemicals produced by these varieties. On the other hand morphological and genetical variations can be observed in traditional rice varieties collected from different places. Therefore, rice varieties collected from different places with same name should also be examined to understand their differences in allelopathic potential.

A highly significant positive relationship was noticed between the two experiments in measuring shoot length, root length and dry matter accumulation (Figure 1). For reduction in seed germination comparatively less but positive correlation was observed (Figure 1). These observations indicate the appropriateness of using both the methods in investigating allelopathic potentiality of rice varieties.

Numerous numbers of researches has been conducted to evaluate allelophthic potential of rice germplasm in laboratory and green house screenings. Allelochemicals releasing to the environment highly differentiate qualitatively and quantitatively with plant growth and development stage and as well as highly inherent with plant origin. Therefore, further experiments under different climatic and management conditions and different developmental stages are important to understand allelopathic potential of rice varieties. Finally extraction and identification of particular chemicals would help to conclude allelopathic potential of various rice varieties. Although not for these rice cultivars several allelopathic chemicals such as p-hydroxybenzoic, ferulic, p-coumaricsyringic and salicylic acids from leaves and straws extracts, decomposing straw, and in rice soil have been identified in other countries (Chung et al., 2001b).

In the present study radish was used as the test crop which is so sensitive to chemicals at low concentrations. Thus, some researchers argued that the species which are highly sensitive to phytotoxin sometimes overestimate the actual allelopathic activity of test plants (Olofsdotter, 2001). Therefore, it is important to repeat this experiment with some common crops such as onion, sesame and bean as these plants did not react too sensitively against allelochemicals at low doses as lettuce, radish and cress did (Xuan et al., 2005) and also with major paddy weed seeds such as Echinochloa crus-galli, Monochoria vaginalis etc. as they display well the allelopathic activities and the weed suppression potential of the screened rice cultivars.

\section{CONCLUSION}

In the present study significant differences $(p \leq 0.05)$ among different rice cultivars in terms of inhibition of radish seed germination and seedling growth were observed. On the basis of measured variables rice varieties Pachchperumal and Herathbanda had highest allelopathic potential than other tested rice varieties. But in farmers perspective it remained as question, that whether the growth inhibition is caused by competition or by allelophathy. Other thing is rice grows in wide range of geological area and allelopathic activity is highly depending not only on its origin but also on environmental and management conditions. Allelophathic effect derives due to the allelochemicals and their bio active concentration. With the change of environmental factors these results may be deviated. 
Therefore, further recommendations of these results must need experiments on different environmental and management conditions as well as allelchemical extraction and identification.

\section{ACKNOWLEDGEMENT}

This work was supported by a grant from TURIS, University of Ruhuna.

\section{REFERENCES}

Ahn JK and Chung IM 2000 Allelopathic potential of rice hulls on germination and seedling growth of barnyardgrass. Agron. J. 92: 1162-1167.

Alam SM, Ala SA, Azmi AR, Khan MR and Ansari R 2001 Allelopathy and its role in agriculture. On line Journal of Biological Sciences, 1: 308-315.

Chou CH 1995 Allelopathy and sustainable agriculture. In: Inderjit Dakshini KMM, Einhellig FA (Eds.) Allelopathy; Organisms, Process, and Application. ACS Symposium Series S82. American Chemical Society, Washington, DC: 211-223.

Chou CH 1999 Role of allelopathy in plant biodiversity and sustainable agriculture. Crit. Rev. Plant Sci. 18: 609-636.

Chung IM, Ahn JK and Yun SJ 2001a Identification of allelopathic compounds from rice (Oryza sativa L.) straw and their biological activity.Can. J. Plant Sci. 81: 815-819.

Chung IM, Ahn JK and Yun SJ 2001b Assessment of allelopathic potential of barnyard grass (Echinochloa crusgalli) on rice (Oryza sativa L.) cultivars Crop Protection 20: 921-928.

Chung IM, Ahn JK, Kim JT and Kim CS 2000 Assessment of allelopathic potentiality and identification of allelopathic compounds on Korean local varieties. Korean J. Crop Sci. 45: 44-49.

Chung IM, Kim KH, Ahn JK and Ju HJ 1997 Allelopathic potential of rice varieties on Echinochloa crus-galli. Korean J. Weed Sci., 17: 52-58.
Chung IM and Miller DA 1995 Allelopathic influence of nine forage grass extracts on germination and seedling growth of alfalfa. Agron. J. 87: 767-772.

Courtois B and Olofsdotter M 1998 Incorporating the allelopathy trait in upland rice breeding programs. In Olofsdotter $\mathrm{M}$ (ed.) Allelopathy in Rice. Manila, Philippines: Int. Rice Research Institute: 57 $-68$.

Dilday RH, Lin J and Yan W 1994 Identification of allelopathy in the USDA-ARS rice germplasm collection. Aust. J. Exp. Agr. 34: 907-910.

Dilday RH, Nastasi P, Li J and Smith Jr. RJ 1991 Allelopathy activity in rice (Oryza sativa L.) against ducksalad (Heteranthera limosa (Sw.)). In: Sustainable Agriculture for the Great Plains, Symposium proceedings, US Department of Agriculture: 193-201.

Fujii Y 1992 The potential for biological control of paddy and aquatic weeds with allelopathy: Allelopathic effect of some rice varieties. Proceedings of the International Symposium on Biological Control and Integrated Management of Paddy and Aquatic Weeds, Tsukuba, Japan: 305-320.

Fujii Y, Parvez SS, Parve MM, Ohmae S and Lida O 2003 Screening of 239 medicinal plant species for allelopathic activity using the Sandwich method. Weed Biol. Manag., 3: 233-241

Garrity DP, Movillon M and Moody K 1992 Differential weed suppression ability in upland rice cultivars. Agron. J. 84: 586 $-591$.

Hassn SM, Rao AN, Bastawisi AO andAidy IR 1994 Weed management in broadcast seeded rice in Egypt. In: Moddy K. (ed.), Constraints, Opportunities and Innovations for Wet-Seeded Rice. IRRI Discussion Paper Series 10. Manila, Philippines: 257-269.

Jonghan K, Eom SH, Kim MJ, Yu CY and Lee YS 2005 Allelopathy of Rice Husk on Barnyardgrass. Journal of Agron- 
omy, 4: 288-292.

Kabir AKMS, Karim SMR, Begum M, Juraimi AS 2010 Allelopathic Potential of Rice Varieties against Spinach (Spinaciaoleracea). Int. J. Agric. Biol. ISSN Print: 1560-8530; ISSN Online: 1814-9596.

Karim SMR, Ismail BS 2007 Allelopathic effects of aqueous extracts from rice leaves and decomposing rice debris on the seed germination and growth of barnyard grass. Proc. 21st Asian Pacific Weed Science Society. Pp. 173-182.

Karim SMR, Momin AMTAM and Begum M 2012 Allelopathic potential of selected rice varieties. African J. of Biotec. 11 (88):15410-15414

Khanh TD, Xuan TD and Chung IM 2007 Rice allelopathy and the possibility for weed management. Annal of Applied Biology. 151: 325-339

Kim KU, Shin DH, Kim HY, Lee IJ and Olofsdotter M 1999 Evaluation of allelopathic potential in rice germplasm. Korean J. of Weed Sci.9 (2): 1-9.

Kruse M, Strandberg $M$ and Strandberg B 2000 Ecological effects of allelopathic plants-A Review. Ministry of Environment and Energy, National Environmental Research Institute, NERI Technical Report, No. 315, Silkeborg, Denmark, pp: 67.

Lin J, Smith Jr. RJ and Dilday RH 1992 Comparison of allelopathic rice and bensulfuron for aquatic weed control in rice. WSSA Abstr.33: 170.

Narwal SS and Tauro P 1994 Allelopathy in Agriculture and Forestry, Jodhpur, India: Scientific Publishers:310 p.

Navarez D and Olofsdotter M 1996 Relay seeding technique for screening allelopathic rice (Oryza sativa). In $\mathrm{H}$. Brown et al. (ed.) Proc. of the 2nd Int. Weed Control Congress, Copenhagen, Denmark. 25-28 June 1996. DJF, Flakkebjerg, Denmark: p. 1285-1290.

Olofsdotter M 1998 Allelopathy in rice. Int. Rice Res. Inst., Makati city, Philippines
City, Philippines.

Olofsdotter M 2001 Rice: A step toward use of allelopathy. Agron. J., 93: 3-8.

Olofsdotter M 1998 Allelopathy for weed control in organic farming. In: Sustainable Agriculture for food, energy and industry-strategies towards achievement. El Bassam, N., R.K. Behl and B. Prochnow, (eds.). James and James Science Publisher, London, pp: 453-465.

Olofsdotter M, Navarez D, Rebulalan M and Streibig JC 1999 Weed-suppressing rice cultivars: Does allelopathy play a role? Weed Res. 39: 441-454.

Olofsdotter M, Navarez K and Moody K 1995 Allelopathic potential in rice (Oryza sativa L.). Ann. Appl. Biol. 127, 543560.

Reigosa MJ, Sanchez-Moreiras A and Gonzalez L 1999 Ecophysiological approach in allelopathy. Crit. Rev. Plant Sci.18: 577-608.

Rice EL 1984 Allelopathy, Second ed. Academic Press, Orlando,Florida.

Rimando AM, Olofsdotter M, Dayan FE and Duke SO 2001 Searching for rice allelochemicals: an example of bioassayguided isolation. Agron. J. 93: 16-20.

Stephenson GR 2000 Herbicide use and world food production: risks and benefits. In: Legere A (ed.), Abstracts of III International Weed Science Congress, Fozdo Iguassu, Brazil, 6-11 June 2000. International Weed Science Society, Corvallis, OR, p. 248.

Valverde B, Riches CR and Caseley JC 2000Prevention and management of herbicide resistant weeds in rice. Published by Grafos SA, Cartago, Costa Rica: 25-30.

Wink M and Twardowski T 1992 Allelochemical properties of alkaloids. Effects on plants, bacteria and protein biosynthesis. In: Allelopathy. Basic and Applied Aaspects. Rizvi SJH and V Rizvi (eds.).Chapman and Hall, London, pp: 129-150.

Wu H, Pratley H, Lemerle D and Haig T 1999 
Crop cultivars with allelopathic capability. Weed Res. 39: 171-180.

Xu M, Wiemann GP, Bueno E, Tiernan M, Wu W, Chung IM, Gershenzon J, Tudzynski B, Sesma A, and Peters RJ 2011 Genetic evidence for natural product mediated plant plant allelopathy in rice. New Phytol. 193(3): 570575.

Xuan TD, Shinkichi T, Khanh TD and Chung IM 2005 Biological control of weeds and plant pathogens in paddy rice by exploiting plant allelopathy: an overview. Crop Protection, 24: 197-206. 